\title{
Beyond intracranial pressure: optimization of cerebral blood flow, oxygen, and substrate delivery after traumatic brain injury
}

Pierre Bouzat ${ }^{1,3}$, Nathalie Sala1,2, Jean-François Payen ${ }^{3,4}$ and Mauro Oddo ${ }^{1,2^{*}}$

\begin{abstract}
Monitoring and management of intracranial pressure (ICP) and cerebral perfusion pressure (CPP) is a standard of care after traumatic brain injury (TBI). However, the pathophysiology of so-called secondary brain injury, i.e., the cascade of potentially deleterious events that occur in the early phase following initial cerebral insult-after TBI, is complex, involving a subtle interplay between cerebral blood flow (CBF), oxygen delivery and utilization, and supply of main cerebral energy substrates (glucose) to the injured brain. Regulation of this interplay depends on the type of injury and may vary individually and over time. In this setting, patient management can be a challenging task, where standard ICP/CPP monitoring may become insufficient to prevent secondary brain injury. Growing clinical evidence demonstrates that so-called multimodal brain monitoring, including brain tissue oxygen $\left(\mathrm{PbtO}_{2}\right)$, cerebral microdialysis and transcranial Doppler among others, might help to optimize CBF and the delivery of oxygen/ energy substrate at the bedside, thereby improving the management of secondary brain injury. Looking beyond ICP and CPP, and applying a multimodal therapeutic approach for the optimization of CBF, oxygen delivery, and brain energy supply may eventually improve overall care of patients with head injury. This review summarizes some of the important pathophysiological determinants of secondary cerebral damage after TBI and discusses novel approaches to optimize CBF and provide adequate oxygen and energy supply to the injured brain using multimodal brain monitoring.
\end{abstract}

Keywords: Traumatic brain injury; Cerebral blood flow; Brain oxygen; Cerebral metabolism; Multimodal monitoring; Cerebral microdialysis; Transcranial Doppler; Neuromonitoring

\section{Review} Introduction

Traumatic brain injury (TBI) first causes primary cerebral lesions related to the initial traumatic brain insult itself. In the early phase following TBI, a complex series of pathologic events triggers the propagation of a "secondary" injury cascade to cerebral areas initially not involved by TBI. Ischemia, hypoxia, and energy dysfunction are important determinants of secondary brain injury. Supporting the injured brain with adequate cerebral blood flow (CBF) and delivery of oxygen and energy substrate therefore is a mainstay of therapy after TBI (Figure 1). Despite this

\footnotetext{
* Correspondence: mauro.oddo@chuv.ch

'Department of Intensive Care Medicine, CHUV-University Hospital, Rue du

Bugnon 46, BH 08.623, CH-1011 Lausanne, Switzerland

${ }^{2}$ Faculty of Biology and Medicine, University of Lausanne, Lausanne,

Switzerland

Full list of author information is available at the end of the article
}

notion and the growing knowledge of posttraumatic secondary brain injury, the management of patients with TBI remains mainly focused to standard intracranial pressure (ICP)/cerebral perfusion pressure (CPP) therapy. Although this approach still constitutes an important part of TBI management [1,2], ICP-based monitoring and treatment alone may not be enough to modify TBI prognosis [3]. This may be partly due to the complexity of TBI pathophysiology and the heterogeneity of TBI lesions [4]. Increasing clinical evidence suggests that multimodal brain monitoring, including brain tissue oxygen tension $\left(\mathrm{PbtO}_{2}\right)$, cerebral microdialysis (CMD), transcranial Doppler (TCD) among others, may optimize CBF and the delivery of oxygen and energy substrates to the injured brain in individual patients. We defined neuromonitor as a monitoring device (invasive or noninvasive) that allows assessment of dynamic changes of cerebral physiology. Based on that, we

\section{Springer}




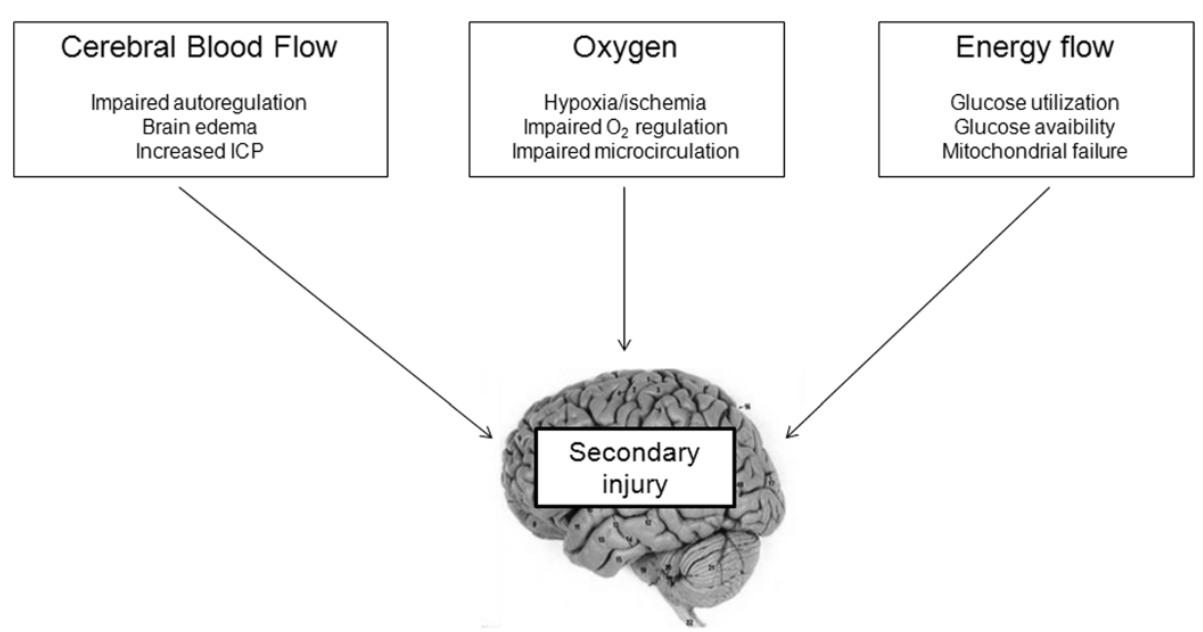

Figure 1 Pathophysiology of secondary cerebral damage after TBI. A schematic view of the pathophysiology of secondary cerebral damage after traumatic brain injury (TBI) that supports the concept of optimizing cerebral blood flow, the delivery of oxygen and the adequate supply of energy substrates.

restricted neuromonitoring techniques described in this review to those monitors allowing measurement of $\mathrm{CBF}$, cerebral oxygenation, and energy substrates at the bedside in the ICU.

\section{Pathophysiology and diagnosis \\ Macrovascular dysfunction}

Under physiological conditions, the relationship between CBF and CPP is linked to the cerebral autoregulatory capacity, thus $\mathrm{CBF}$ remains constant over a wide range of CPP. After TBI, depending on the nature of the lesion (diffuse vs. focal), there may be a large heterogeneity in brain autoregulatory capacities [5]. Reduction of cerebrovascular reserve and impairment of cerebral autoregulation cause CBF to become increasingly dependent on CPP, thus CBF may be inadequate/insufficient despite CPP is within so-called "normal" ranges $(50-70 \mathrm{mmHg}$ ) [6]. In addition, apart from the individual relationship between CBF and $\mathrm{CPP}$, secondary elevations of ICP also could contribute to further decrease CPP and aggravate ischemia.

The decrease of CBF after TBI was well documented by different studies using xenon-enhanced computed tomography (CT) [5] or positron emission tomography (PET) [7] that revealed heterogeneous regional disturbance of CBF. It also is important to stress the point that reduced CBF does not necessarily mean ischemia. Rather, the balance between $\mathrm{CBF}$ and cerebral metabolic rate of oxygen $\left(\mathrm{CMRO}_{2}\right)$ determines whether the tissue is ischemic or not. For example, the decrease of CBF can be matched by a decrease of cerebral metabolic rate of oxygen $\left(\mathrm{CMRO}_{2}\right)$, implying adequate CBF and preserved metabolic coupling, as it can be seen with deep sedation. In these circumstances, so-called metabolic autoregulation is the cause of matched reduction of $\mathrm{CBF}$, in the absence of ischemia.
Conversely, when $\mathrm{CBF}$ reduction is greater than $\mathrm{CMRO}_{2}$ decrease, CBF becomes inadequate to satisfy energy demand, exposing the tissue to hypoperfusion and eventually ischemia. Importantly, low CBF and ischemia might occur despite CPP $\approx 65-75 \mathrm{mmHg}$ [8]. Hence, CPP is not reliable to assess $\mathrm{CBF}$ in individual patients and other bedside tools are necessary.

Among noninvasive methods, TCD has been most studied and is an accurate tool to assess brain perfusion at the bedside. The technique consists in the measure of middle cerebral artery CBF velocities (CBFV; systolic, diastolic and mean) and the calculation of the pulsatility index $[\mathrm{PI}=$ (systolic $\mathrm{CBFV}$ - diastolic CBFV) $/$ mean CBFV]. Reduced CBF, e.g., because of elevated ICP or low $\mathrm{PaCO}_{2}$, is diagnosed by low diastolic CBFV, a peaked waveform, and an elevated PI > 1.2-1.3 (Figure 2A). TCD has recently been used in the emergency room to detect high ICP/low CBF in TBI patients [9].

Invasive thermal diffusion flowmetry (TDF) is based on the insertion of an intraparenchymal probe (Thermal Diffusion Probe; Hemedex Cambridge, MA) generally next to $\mathrm{ICP} / \mathrm{PbtO}_{2}$ probes. The technique uses thermal conductivity of the brain tissue and allows measuring regional cerebral blood flow ( $\mathrm{rCBF}$ ) in a quantitative way. The TDF technique was used in TBI to assess cerebral autoregulation and $\mathrm{CO}_{2}$ vasoreactivity and to calculate local cerebral vascular resistance. However, limitations of TDF, such as fever, sensor displacement, and the small area monitored, hindered its clinical application. Vajkoczy et al. showed good agreement between TDF and xenonCT for regional CBF measurements [10]. Recent studies showed the potential utility of TDF, in combination with $\mathrm{PbtO}_{2}$, to optimize the management of CPP in braininjured patients. In SAH patients, Muench et al. used 


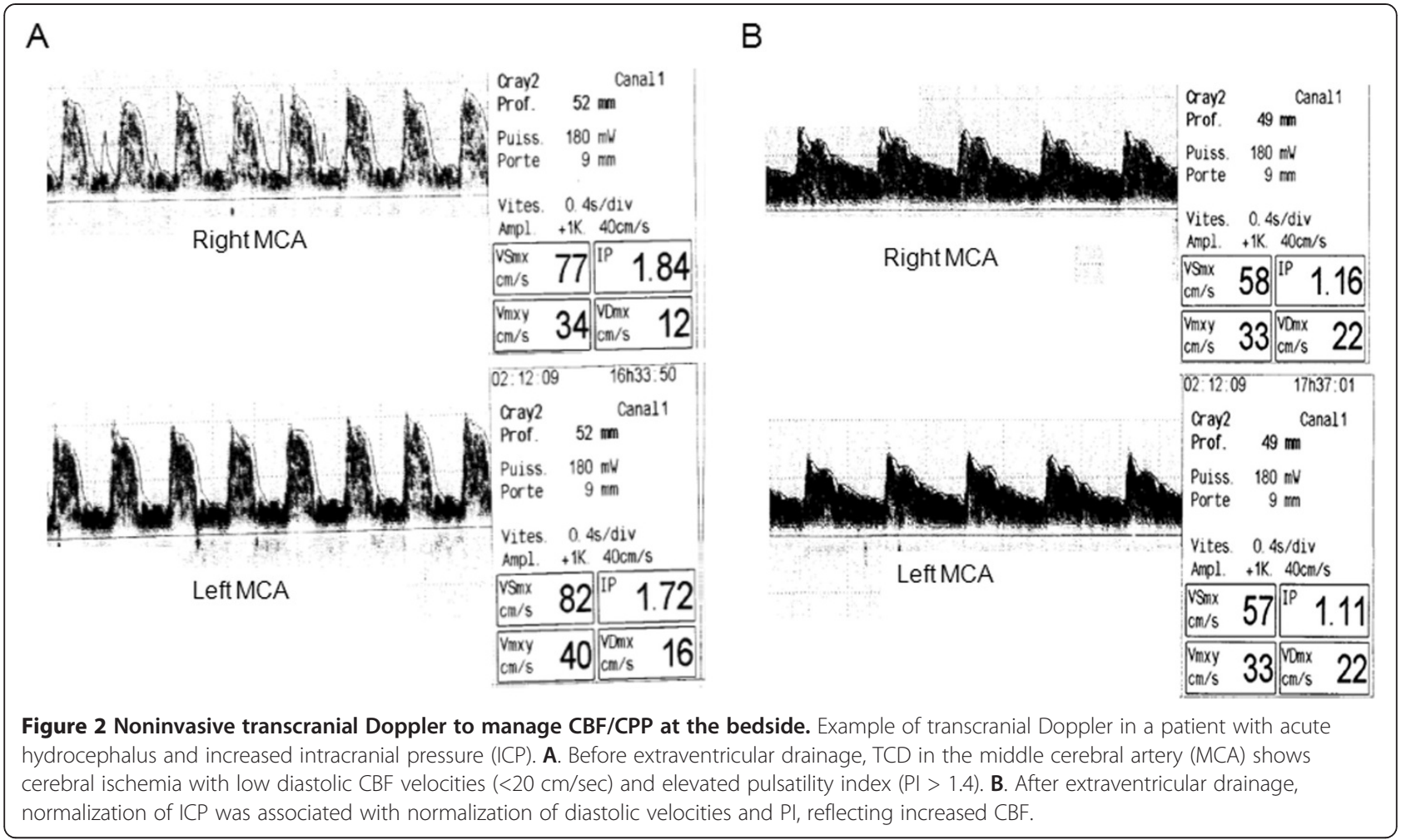

TDF to guide medical therapy of delayed cerebral ischemia [11] and show that MAP augmentation was the only single useful intervention to improve $\mathrm{CBF}$ and $\mathrm{PbtO}_{2}$, whilst hypervolemia and hemodilution had only marginal effects at best, supporting recommended practices of induced hypertension alone over "triple- $\mathrm{H}$ " therapy for the medical management of delayed cerebral ischemia. After TBI, TDF may guide CPP management at the bedside and identify individual MAP/CPP thresholds [12]. Precise quantification of $\mathrm{rCBF}$ with TDF remains highly dependent on stable patient temperature and may be altered significantly in conditions of severe hyperthermia and rapid fluctuations of patient's temperature. TDF seems a promising tool that may progressively become part of brain multimodality monitoring in the future. However, so far data are limited to small single-centre studies.

\section{Microvascular dysfunction}

Macrovascular disturbances and reduced/inadequate CBF are not the only determinants of secondary ischemia. Impairment of the microvascular circulation also could play a key role in the constitution of secondary brain damages. Evidence for post-TBI microcirculatory dysfunction is both experimental and clinical. Marked disturbances in microcirculatory blood flow can be due to swelling of astroglial foot processes and compression of surrounding capillaries [13-15], or the formation of thrombi in the cerebral microcirculation [16]. In addition, electron microscopy showed endothelial edema, vacuolization and pinocytic vesicles [13,14,17]. Microvascular edema might cause increased barriers for oxygen diffusion with reduction of cellular oxygen delivery despite the absence of frank cerebral ischemia [17]. Microvascular damage accounts for the inability of pericontusional tissue to increase the oxygen extraction fraction $\left(\mathrm{OEF}=\mathrm{SaO}_{2}-\mathrm{SvO}_{2} / \mathrm{SaO}_{2}\right)$ in response to reduction of $\mathrm{CBF}$ induced by hyperventilation. Considering capillaries architecture as a central role for oxygen delivery to the cell [18], heterogeneity of red blood cell transit time into capillaries could lead to hypoxia in the injured brain, despite normal CBF.

The direct measurement of $\mathrm{PbtO}_{2}$ is now increasingly recognized as part of the bedside neuromonitoring after severe TBI [19] and can be used to detect brain hypoxia. Low $\mathrm{PbtO}_{2}$ has been reported to be associated with worse outcome after TBI [20,21], independently of brain hypoperfusion detected by ICP/CPP monitoring [22].

Laser Doppler flowmetry (LDF) is an invasive fiberoptic laser probe that can be inserted into brain parenchyma to measure regional perfusion of a tissue volume of approximately $1 \mathrm{~mm}^{3}$. Contrary to TDF, LDF provides only qualitative-but not quantitative-measurements of microvascular perfusion [23]. Routine use of this optical technique remains complex and artifacts, such as heterogeneity of microvascular architecture, probe motion, room temperature, and strong external light and sound may compromise data quality [24]. 


\section{Energy dysfunction}

Brain activation and any augmentation of energy demand are followed by an increase in CBF and OEF. What is peculiar to the brain is its "avidity" for glucose utilization. Raichle and colleagues demonstrated that neuronal activation was followed by an increase in CBF and glucose utilization $(\approx 30 \%)$ without a proportionate increase of OEF and cerebral metabolic rate of oxygen $\left(\mathrm{CMRO}_{2} ; \approx 6 \%\right)$ : this phenomenon is known as brain metabolic uncoupling [25]. Experimental and clinical studies have shown that glucose utilization may increase dramatically after TBI, in the absence of oxygen or CBF limitation (cerebral hyperglycolysis) [26-28]. This may lead to a reduction of cerebral glucose below the critical level and to a state of brain energy dysfunction or crisis $[28,29]$. In addition, cerebral oxidative metabolism may also be impaired due to mitochondrial dysfunction, thereby resulting in reduction of $\mathrm{CMRO}_{2}$ up to $50 \%$ in the acute period after TBI [30]. Altogether these findings support the view that nonischemic mechanisms are implicated in the pathophysiology of TBI.

\section{Bedside clinical approach Cerebral blood flow optimization Determining the optimal CPP}

Despite its limitations, the measure of ICP for the calculation of CPP is essential to the management of TBI at the bedside. Low CPP was well correlated with poor outcome in several studies [31,32]. All of these studies determined a critical ischemic threshold of CPP between 50 and $60 \mathrm{mmHg}$. Accordingly, and due to lack of benefit in increasing CPP to higher levels [33], actual recommendations from the Brain Trauma Foundation suggest a target of CPP between 50 and $70 \mathrm{mmHg}$ [34]. However, recent clinical studies in TBI patients have repeatedly demonstrated that the so-called "optimal" CPP (i.e., the CPP threshold below which secondary ischemia occurs) differs individually and might vary over time within each single patient $[6,8,35]$. Arterial blood pressure/intracranial pressure (ICP)-derived pressure reactivity index (PRx) could be used to assess cerebrovascular pressure reactivity [36]. This index relies on spontaneous changes of arterial blood pressure and is calculated using a time correlation method. PRx, when averaged over specific CPP thresholds, demonstrated a U-shaped curve suggesting a specific relationship with the level of CPP. Although its utility can be debated, PRx may be useful in determining optimal CPP in individual patients. The reader also can refer to recent reviews on this particular topic [37].

Bedside measurement of $\mathrm{PbtO}_{2}$ also can be used as a surrogate marker of $\mathrm{CBF}$. In agreement with recent data indicating that the venous fraction within cortical microvasculature exceeds $70 \%$, it is suggested that $\mathrm{PbtO}_{2}$ predominantly reflects venous $\mathrm{PO}_{2}$ [38]. Among the factors affecting $\mathrm{PbtO}_{2}$, the effect of decreased cerebral perfusion pressure (CPP) and CBF has been the most studied [39]. $\mathrm{PbtO}_{2}$ appears to correlate well with regional CBF and the relationship follows the autoregulation curve regulating $\mathrm{CBF}$ along a wide range of mean arterial pressure (MAP) [40]. The fact that increase in $\mathrm{PbtO}_{2}$ can be obtained with $\mathrm{CPP}$ and MAP augmentation further supports the notion that $\mathrm{PbtO}_{2}$ is a good marker of $\mathrm{CBF}$ and cerebral ischemia in certain conditions. Rosenthal and colleagues, however, using parenchymal TDP and $\mathrm{PbtO}_{2}$ monitoring, showed that $\mathrm{PbtO}_{2}$ more appropriately reflects the product of $\mathrm{CBF}$ and arteriovenous oxygen tension difference $\left(\mathrm{AVTO}_{2}\right)$ [41]. Based on the formula $\mathrm{PbtO}_{2}=\mathrm{CBF} \cdot \mathrm{AVTO}_{2}$, reduced $\mathrm{PbtO}_{2}$ occurs frequently because of low CBF. However, $\mathrm{PaO}_{2}$ also is an important determinant of $\mathrm{PbtO}_{2}$ [42] and additional pathological events (e.g., impaired lung function [43] or impaired $\mathrm{O}_{2}$ extraction due to increased gradients for oxygen diffusion in injured brain tissue [17]) might reduce $\mathrm{PbtO}_{2}$, in the absence of reduced CBF. Hemoglobin concentration also affects $\mathrm{PbtO}_{2}$ and reduced hemoglobin concentration below $9 \mathrm{~g} / \mathrm{dl}$ may aggravate brain hypoxia [44].

CBF being an important determinant of $\mathrm{PbtO}_{2}$, it is possible to test at the bedside the individual response of $\mathrm{PbtO}_{2}$ to a vasopressor-induced increase of $\mathrm{CPP} /$ mean arterial pressure (MAP). This has originally been described as the oxygen reactivity index (ORx) and can be used to assess the state of cerebral autoregulation [45]. In practice, the $\mathrm{PbtO}_{2}$ response can be used to guide the management of CPP at the bedside. In pathological situations, the relationship between $\mathrm{PbtO}_{2}$ and CPP may become linear (Figure 3), hence manipulating CPP to maintain $\mathrm{PbtO}_{2}>15-20 \mathrm{mmHg}\left(\mathrm{PbtO}_{2}\right.$-directed strategy) might optimize $\mathrm{CBF}$ and avoid secondary ischemia $[21,46]$. Additional therapeutic interventions that may improve $\mathrm{PbtO}_{2}$ are described in section III.2 and Figure 4.

Measuring CBF velocities with TCD also could help physicians to manage CPP. A PI above 1.4 and a diastolic CBFV below $20 \mathrm{~cm} \cdot \mathrm{sec}^{-1}$ are characteristic TCD markers of ischemia after severe TBI [47], as illustrated in Figure 2B. In centers with clinical expertise, TCD is increasingly used to assess brain compliance, CPP and impending cerebral ischemia in patients in whom invasive ICP is not available. For example, TCD has been used in the early phase in the emergency room to detect brain ischemia non-invasively in TBI patients [47], before ICP monitoring was inserted. TCD also can be used to test brain autoregulation and vasoreactivity to $\mathrm{CO}_{2}[36]$.

\section{$\mathrm{PaCO}_{2}$}

A reduction in $\mathrm{PaCO}_{2}$ results in a proportional reduction of CBF and cerebral blood volume. While this could be temporarily useful in decreasing elevated ICP, it must be underlined that prolonged aggressive hyperventilation $\left(\mathrm{PaCO}_{2}<25-30 \mathrm{mmHg}\right)$ is deleterious for patients with 


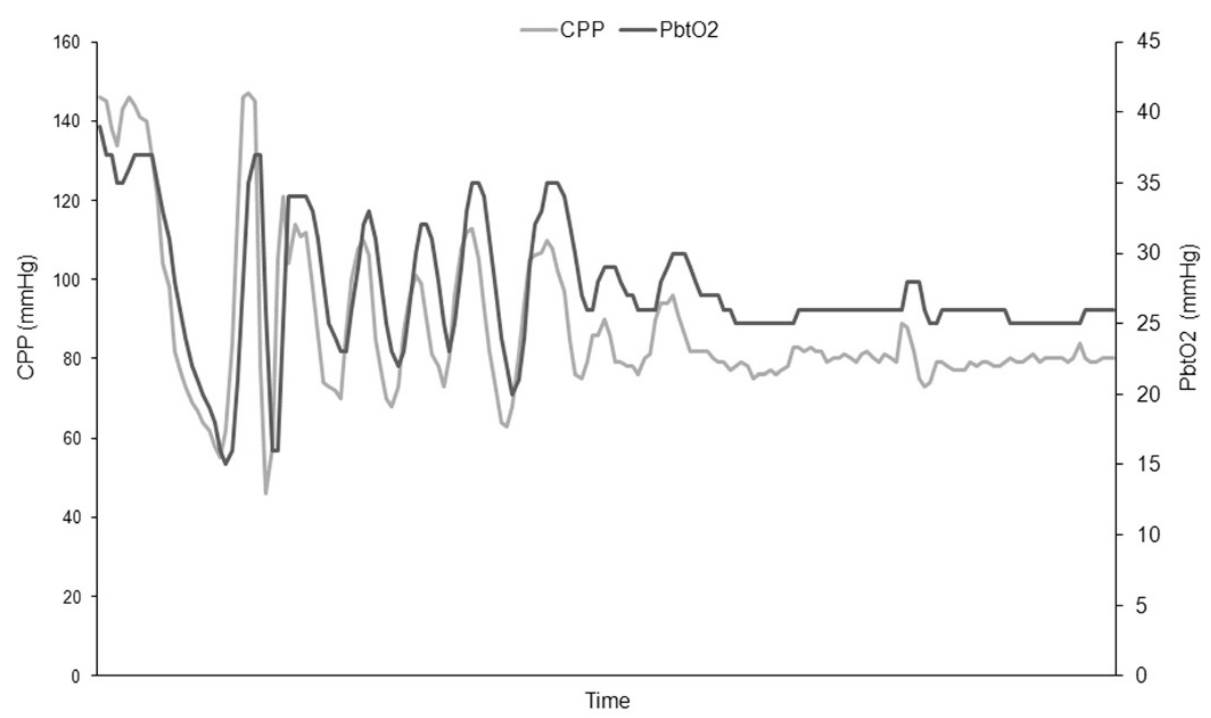

Figure $3 \mathrm{PbtO}_{2}$-guided management of CPP in individual patients. Example of a patient exhibiting a linear correlation between CPP and $\mathrm{PbtO}_{2}$, which suggests impaired cerebrovascular reactivity (elevated oxygen reactivity index, $\mathrm{ORx},>0.7$ ). In this case, higher CPP thresholds $\left(>80 \mathrm{mmHg}\right.$ ) are required to prevent secondary ischemia $\left(\mathrm{PbtO}_{2}<20 \mathrm{mmHg}\right)$. This is an example of how $\mathrm{PbtO}_{2}$ monitoring may guide CPP management and the setting of "optimal" CPP at the bedside.

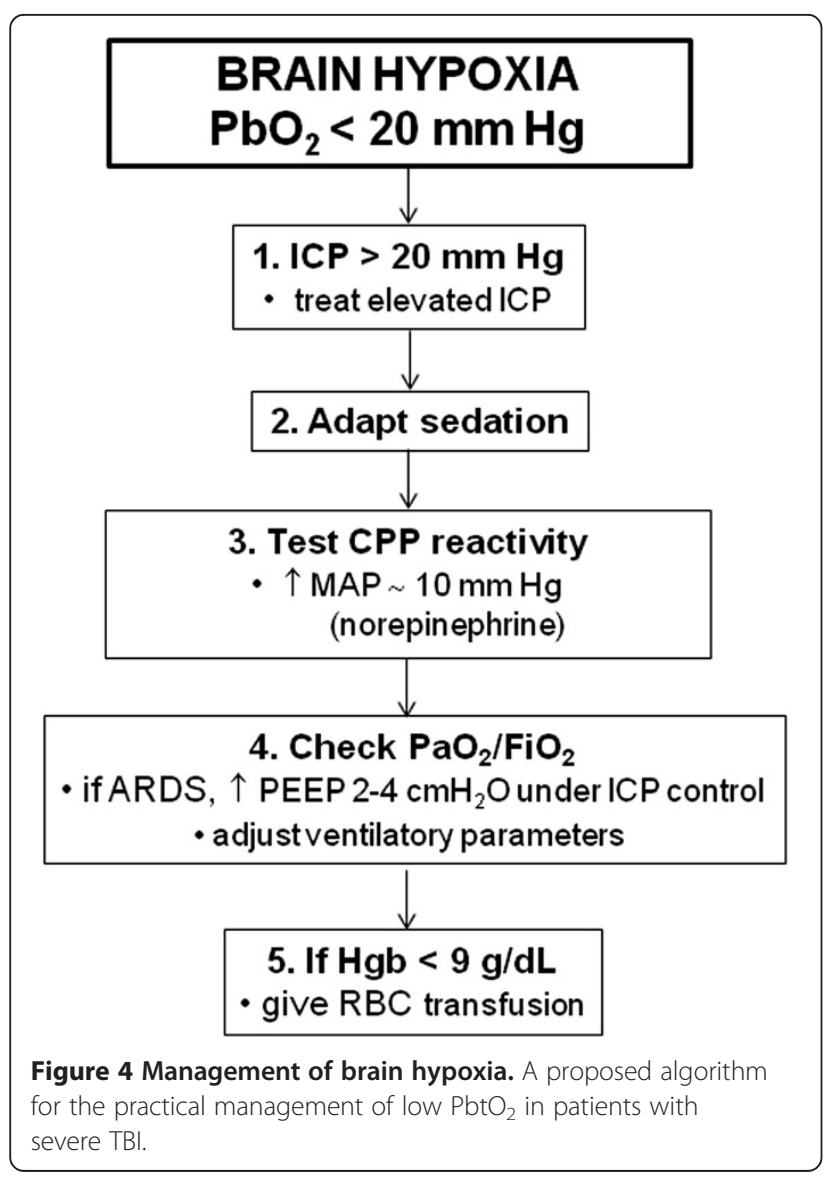

TBI by decreasing CBF below the ischemic threshold [48,49]. Regular measurements of $\mathrm{PaCO}_{2}$ with arterial blood gas analysis and continuous monitoring of endtidal $\mathrm{CO}_{2}\left(\mathrm{EtCO}_{2}\right)$ must be achieved in every TBI patients to manage CBF variations secondary to $\mathrm{PaCO}_{2}$. Again, $\mathrm{PbtO}_{2}$ can be used to manage $\mathrm{PaCO}_{2}$ at the bedside [41,50]. Using $\mathrm{CO}_{2}$ reactivity, TCD also detects brain perfusion changes related to $\mathrm{PaCO}_{2}$ noninvasively and may be used to evaluate cerebral vasoreactivity and to tailor individual $\mathrm{PaCO}_{2}$ after TBI [51].

\section{Brain oxygen supply}

Cerebral blood flow is one of the most important determinants of brain oxygen delivery. As discussed previously, arterial blood pressure and CPP are the major modifiable variables of brain oxygenation. This implicates that manipulating blood pressure and CPP may be the first and often the most effective intervention to optimize CBF and oxygen supply to injured brain tissue. Second-tier interventions to improve $\mathrm{PbtO}_{2}$ despite CPP modifications include optimization of systemic oxygenation (lung protective ventilation and maintenance of strict normoxia) [43] and red blood cell transfusion if hemoglobin is below $9 \mathrm{~g} / \mathrm{dl}$ [44] (Figure 4).

However, other mechanisms may reduce brain tissue oxygenation. Among these, diffusion-limited oxygen delivery plays a key role and might explain why $\mathrm{PbtO}_{2}$ can be reduced despite oxygen delivery $\left(\mathrm{PvO}_{2}\right)$ and $\mathrm{CBF}$ are normal [17]. In clinical practice, this may explain why in some circumstances brain tissue hypoxia can occur despite ICP/CPP being within normal ranges [22]. Without 
anemia or hypoxia, low $\mathrm{PbtO}_{2}$ despite adequate CBF probably reflects microcirculatory dysfunction and pericapillary edema [17]. This has important implications for the management of $\mathrm{PbtO}_{2}$ and the response of $\mathrm{PbtO}_{2}$ to therapeutic interventions.

\section{Hyperoxia}

One strategy to force diffusion barriers is to increase the fraction of dissolved oxygen with hyperoxia. All studies have demonstrated a robust effect of increasing $\mathrm{FiO}_{2}$ on brain oxygenation [52]. Whether this increase of $\mathrm{PbtO}_{2}$ is beneficial for patients remains controversial, probably due to the ability of the brain to use oxygen, i.e., the oxidative metabolism. Therefore, hyperoxia could benefit some patients in distinct cerebral areas [42]. However, considering the absence of strong evidence, this strategy is not recommended in TBI patients.

\section{Erythropoietin}

Erythropoietin (Epo) is a promising neuroprotective treatment in experimental models of TBI [53] and exerts significant cerebral antiedematous effect [54]. In an experimental model of diffuse TBI, it was recently shown that Epo, administrated intravenously up to 30 minutes after TBI, not only reverses cerebral edema but also significantly restores brain tissue oxygenation to normal levels [55]. Electronic microscopy revealed a decrease of astrocytic end-foot swelling, which could improve red blood cell transit time. Hence, Epo, given its combined effects on brain edema, perfusion, and oxygenation may be particularly promising for the treatment of TBI. The ongoing "Epo-TBI" study will clarify therapeutic potentials of Epo in patients with TBI (clinialtrials.gov: NCT00987454).

\section{Brain energy supply}

Cerebral microdialysis (CMD) has largely contributed to a better understanding of the pathophysiology of acute brain dysfunction after TBI and was introduced recently as an additional bedside neuromonitoring tool in this context. CMD consists in the placement of an intraparenchymal probe that has on its tip a semi-permeable dialysis membrane. A cerebrospinal fluid-like solution, infused through this catheter, allows hourly sampling of patients' brain extracellular fluid into microvials for bedside analysis [56]. CMD provides continuous monitoring of cerebral energy metabolism at the bedside and the measurement of absolute and dynamic changes of brain extracellular concentrations of glucose, pyruvate, and lactate. Additional markers, such as glutamate (excitotoxicity) and glycerol (membrane integrity), can be measured $[57,58]$. The clinical utility of CMD is mainly to detect impending ischemia/ hypoxia and to assess the energetic state of the injured human brain $[19,59,60]$. Abnormal lactate/pyruvate ratio (LPR) is defined by a LPR > 25 [56], and this threshold is associated with worse outcome after TBI [57]. Others also used LPR > 40 as marker of cell energy crisis [56]. In clinical practice, values $>35-40$ are used to start therapeutic interventions. Elevated LPR can be due to ischemia/hypoxia: in these circumstances, elevated lactate is accompanied by low pyruvate, as well as low cerebral glucose and brain oxygen. "Ischemic/hypoxic" LPR elevations can reach very high levels, well above 40. A second pattern also can be seen, where elevated lactate/normal-to-high pyruvate is seen and

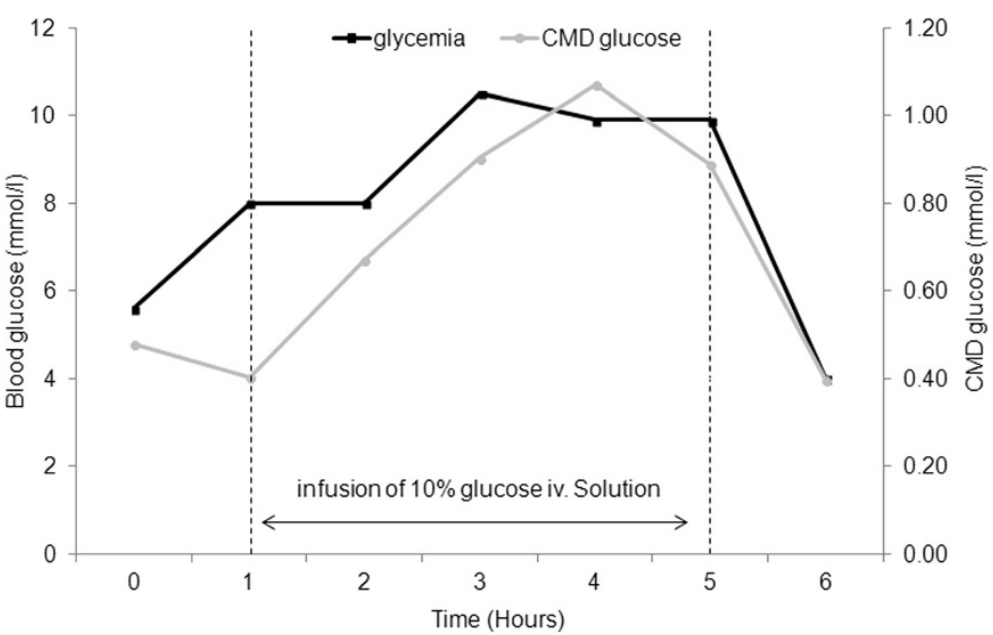

Figure 5 Cerebral microdialysis-guided management of glycemic control in individual patients. Example of a patient showing a linear relationship between blood and brain glucose, measured by cerebral microdialysis (CMD) glucose. Because of low CMD glucose $<1 \mathrm{mmol} / \mathrm{L}$, infusion of a $10 \%$ glucose solution was administered and was associated with a parallel increase of both arterial blood and CMD glucose. This illustrates the potential value of CMD for the management of blood glucose control in patients with severe brain injuries, aiming to prevent secondary systemic insults (brain glucopenia in this case). 
indicates the cause of LPR elevation is nonischemic in nature and can be due to hyperglycolysis [61] or mitochondrial dysfunction [28]. In this second "nonischemic" pattern levels of LPR are often only slightly elevated (LPR 40-50). Elevated LPR is therefore not only a marker of ischemia, but rather reflects the metabolic state of the tissue.

\section{Brain glucose supply and blood glucose control}

Cerebral microdialysis has greatly contributed to better manage glucose control in TBI patients at high risk for secondary brain injury $[62,63]$. Glucose is the main energy source for the human brain. Therefore adequate glucose supply is crucial to maintain brain function. Supply of glucose is provided by selective transporters (GLUT) that allow glucose diffusion across the blood brain barrier to brain cells. Glucose supply to the brain is highly dependent on the availability of glucose from the systemic circulation (Figure 5) [64]. Therefore, so-called "intensive" blood glucose control with the use of insulin therapy may reduce brain glucose availability and potentially increase energy dysfunction or aggravate metabolic distress [63,65-67]. Moderate $(\approx 8-10 \mathrm{mmol} / \mathrm{L})$ vs. intensive $(\approx 4.5-6 \mathrm{mmol} / \mathrm{L})$ glucose control does not confer any benefit on TBI outcome [68]. Using CMD, systemic glucose concentration can be targeted to CMD glucose, to avoid neuroglucopenia $(\mathrm{CMD}<1 \mathrm{mmol} / \mathrm{L})$. In some patients, this can occur already at blood glucose levels $<8 \mathrm{mmol} / \mathrm{l}$, and therefore systemic glucose must be adapted to avoid low brain glucose, by keeping blood glucose at $8-10 \mathrm{mmol} / \mathrm{L}$, if necessary by giving slow infusion of $10 \%$ i.v. glucose. It is important to realize however that reduced brain glucose can be due to other reasons, including ischemia/energy crisis, elevated ICP/low CPP; in these circumstances, these causes must be treated first. Given these findings, when CMD is available precise blood glucose levels should be targeted to CMD glucose to avoid levels $<1 \mathrm{mmol} / \mathrm{L}$. Otherwise, moderate blood glucose control $(\approx 8-10 \mathrm{mmol} / \mathrm{L})$ is recommended for the management of patients with severe brain injury.

\section{Alternative energy substrates}

Glucose utilization involves two different pathways. Oxidative phosphorylation is the energy-generating biochemical process whereby pyruvate, produced by glycolysis, is oxidized to $\mathrm{CO}_{2}$ and $\mathrm{H}_{2} \mathrm{O}$ with the production of 30 moles of ATP. This process requires oxygen. Glycolysis is the energy-generating biochemical process whereby glucose is converted to pyruvate and lactate with the net production of 2 moles of ATP. This process is nonoxidative, producing lactate [25].

Evidence from in vitro and in vivo studies demonstrates that lactate is an important energy substrate for neurons [69], particularly in conditions of hypoxia [70]. Recently, evidence of brain lactate utilization in humans with acute brain injury has been suggested [61,71].
Exogenous administration of lactate with the use of sodium lactate perfusions improves cerebral performance during intense exercise [72] and in diabetic patients [73], with sparing of brain glucose [74]. Preliminary studies in TBI patients suggest that sodium lactate solutions may be a future therapeutic strategy, potentially more effective to lower ICP than mannitol [75].

\section{Conclusions}

$\mathrm{ICP} / \mathrm{CPP}$ monitoring is important after TBI since CBF is highly dependent on CPP below the lower limit of cerebral autoregulation, i.e., $\mathrm{CPP}<50 \mathrm{mmHg}$. Above the ischemic threshold, tailoring CPP for each patient needs a more comprehensive approach guided to brain multimodal monitoring to target $\mathrm{CBF}$, oxygen delivery, and supply of brain energy substrates individually. Intraparenchymal $\mathrm{PbtO}_{2} \mathrm{re}-$ flects the complex interaction between CBF and oxygen delivery/consumption by the injured brain. As a result, $\mathrm{PbtO}_{2}$-targeted therapy might help managing $\mathrm{CPP}$ and prevent secondary cerebral ischemia and can be considered as a useful addition to standard ICP monitoring. Transcranial Doppler also can help to diagnose reduced CBF and elevated ICP at the bedside noninvasively and may help to direct in the early phase the need for additional intracranial monitoring and for emergent surgical interventions. Cerebral microdialysis provides essential information on brain metabolism and the availability of main energy substrates (mainly glucose) and also is potentially useful to detect secondary delayed cerebral ischemia and manage blood glucose control. Beyond ICP monitoring, contemporary management of severe TBI patients is increasingly based upon a more comprehensive clinical approach that must not be limited to ICP/CPP therapy but also includes the individual optimization of CBF, oxygen, and energy substrate delivery guided by bedside brain multimodal monitoring.

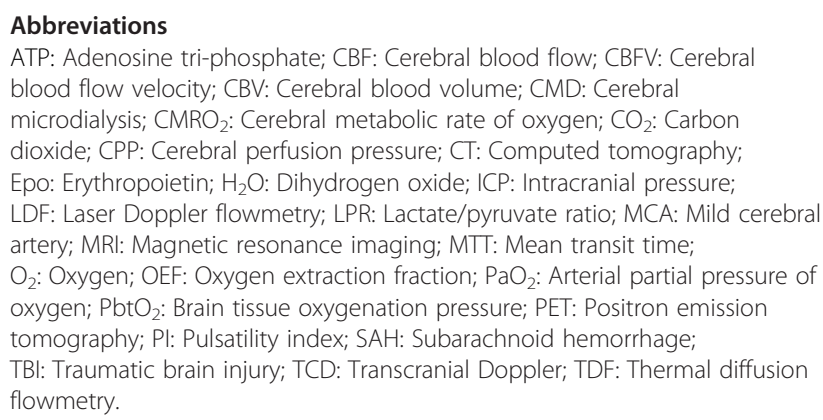

\section{Competing interests}

The author's declare that they have no competing interests.

\section{Authors' contributions}

$\mathrm{PB}, \mathrm{NS}$, JFP and MO drafted the manuscript. All authors read and approved the final version.

\section{Author details}

'Department of Intensive Care Medicine, CHUV-University Hospital, Rue du Bugnon 46, BH 08.623, CH-1011 Lausanne, Switzerland. 'Faculty of Biology 
and Medicine, University of Lausanne, Lausanne, Switzerland. ${ }^{3}$ Joseph Fourier University, Grenoble, France. ${ }^{4}$ Department of Anesthesiology and Intensive Care Medicine, University Hospital, Grenoble, France.

Received: 12 March 2013 Accepted: 25 June 2013

Published: 10 July 2013

\section{References}

1. Patel HC, Menon DK, Tebbs S, Hawker R, Hutchinson PJ, Kirkpatrick PJ: Specialist neurocritical care and outcome from head injury. Intensive Care Med 2002, 28:547-553.

2. Stein SC, Georgoff P, Meghan S, Mirza KL, El Falaky OM: Relationship of aggressive monitoring and treatment to improved outcomes in severe traumatic brain injury. J Neurosurg 2010, 112:1105-1112.

3. Chesnut RM, Temkin N, Carney N, Dikmen S, Rondina C, Videtta W, Petroni G, Lujan S, Pridgeon J, Barber J, et al: A trial of intracranial-pressure monitoring in traumatic brain injury. N Engl J Med 2012, 367:2471-2481.

4. Maas Al, Stocchetti N, Bullock R: Moderate and severe traumatic brain injury in adults. Lancet Neurol 2008, 7:728-741.

5. Bouma GJ, Muizelaar JP, Bandoh K, Marmarou A: Blood pressure and intracranial pressure-volume dynamics in severe head injury: relationship with cerebral blood flow. J Neurosurg 1992, 77:15-19.

6. Jaeger M, Dengl M, Meixensberger J, Schuhmann MU: Effects of cerebrovascular pressure reactivity-guided optimization of cerebral perfusion pressure on brain tissue oxygenation after traumatic brain injury. Crit Care Med 2010, 38:1343-1347.

7. Scalfani MT, Dhar R, Zazulia AR, Videen TO, Diringer MN: Effect of osmotic agents on regional cerebral blood flow in traumatic brain injury. J Crit Care 2012, 27:526. e527-512.

8. Coles JP, Steiner LA, Johnston AJ, Fryer TD, Coleman MR, Smieleweski P, Chatfield DA, Aigbirhio F, Williams GB, Boniface S, et al: Does induced hypertension reduce cerebral ischaemia within the traumatized human brain? Brain 2004, 127:2479-2490.

9. Bouzat P, Francony G, Declety P, Genty C, Kaddour A, Bessou P, Brun J, Jacquot C, Chabardes S, Bosson JL, Payen JF: Transcranial Doppler to screen on admission patients with mild to moderate traumatic brain injury. Neurosurgery 2011, 68:1603-1609. discussion 1609-1610.

10. Vajkoczy P, Roth H, Horn P, Lucke T, Thome C, Hubner U, Martin GT, Zappletal C, Klar E, Schilling L, Schmiedek P: Continuous monitoring of regional cerebral blood flow: experimental and clinical validation of a novel thermal diffusion microprobe. J Neurosurg 2000, 93:265-274.

11. Muench E, Horn P, Bauhuf C, Roth H, Philipps M, Hermann P, Quintel M, Schmiedek P, Vajkoczy P: Effects of hypervolemia and hypertension on regional cerebral blood flow, intracranial pressure, and brain tissue oxygenation after subarachnoid hemorrhage. Crit Care Med 2007, 35:1844-1851. quiz 1852

12. Rosenthal G, Sanchez-Mejia RO, Phan N, Hemphill JC 3rd, Martin C, Manley GT: Incorporating a parenchymal thermal diffusion cerebral blood flow probe in bedside assessment of cerebral autoregulation and vasoreactivity in patients with severe traumatic brain injury. J Neurosurg 2011, 114:62-70

13. Bullock R, Maxwell WL, Graham DI, Teasdale GM, Adams JH: Glial swelling following human cerebral contusion: an ultrastructural study. J Neurol Neurosurg Psychiatry 1991, 54:427-434

14. Vaz R, Sarmento A, Borges N, Cruz C, Azevedo I: Ultrastructural study of brain microvessels in patients with traumatic cerebral contusions. Acta Neurochir (Wien) 1997, 139:215-220.

15. Rodriguez-Baeza A, Reina-de la Torre F, Poca A, Marti M, Garnacho A: Morphological features in human cortical brain microvessels after head injury: a three-dimensional and immunocytochemical study. Anat Rec $A$ Discov Mol Cell Evol Biol 2003, 273:583-593.

16. Schwarzmaier SM, Kim SW, Trabold R, Plesnila N: Temporal profile of thrombogenesis in the cerebral microcirculation after traumatic brain injury in mice. J Neurotrauma 2010, 27:121-130.

17. Menon DK, Coles JP, Gupta AK, Fryer TD, Smielewski P, Chatfield DA Aigbirhio F, Skepper JN, Minhas PS, Hutchinson PJ, et al: Diffusion limited oxygen delivery following head injury. Crit Care Med 2004, 32:1384-1390

18. Jespersen $S N$, Ostergaard $L$ : The roles of cerebral blood flow, capillary transit time heterogeneity, and oxygen tension in brain oxygenation and metabolism. J Cereb Blood Flow Metab 2012, 32:264-277.
19. Andrews PJ, Citerio G, Longhi L, Polderman K, Sahuquillo J, Vajkoczy P, Neuro-Intensive C, Emergency Medicine Section of the European Society of Intensive Care M: NICEM consensus on neurological monitoring in acute neurological disease. Intensive Care Med 2008, 34:1362-1370.

20. van den Brink WA, van Santbrink H, Steyerberg EW, Avezaat CJ, Suazo JA, Hogesteeger C, Jansen WJ, Kloos LM, Vermeulen J, Maas Al: Brain oxygen tension in severe head injury. Neurosurgery 2000, 46:868-876. discussion 876-868.

21. Maloney-Wilensky E, Gracias V, Itkin A, Hoffman K, Bloom S, Yang W, Christian S, LeRoux PD: Brain tissue oxygen and outcome after severe traumatic brain injury: a systematic review. Crit Care Med 2009, 37:2057-2063.

22. Oddo M, Levine JM, Mackenzie L, Frangos S, Feihl F, Kasner SE, Katsnelson $M$, Pukenas B, Macmurtrie E, Maloney-Wilensky E, et al: Brain hypoxia is associated with short-term outcome after severe traumatic brain injury independently of intracranial hypertension and low cerebral perfusion pressure. Neurosurgery 2011, 69:1037-1045. discussion 1045.

23. Fukuda O, Endo S, Kuwayama N, Harada J, Takaku A: The characteristics of laser-Doppler flowmetry for the measurement of regional cerebral blood flow. Neurosurgery 1995, 36:358-364.

24. Miles B, Davis S, Crandall C, Ellis E 3rd: Laser-Doppler examination of the blood supply in pericranial flaps. J Oral Maxillofac Surg 2010, 68:1740-1745.

25. Raichle ME, Mintun MA: Brain work and brain imaging. Annu Rev Neurosci 2006, 29:449-476.

26. Chen SF, Richards HK, Smielewski P, Johnstrom P, Salvador R, Pickard JD, Harris NG: Relationship between flow-metabolism uncoupling and evolving axonal injury after experimental traumatic brain injury. $J$ Cereb Blood Flow Metab 2004, 24:1025-1036.

27. Bergsneider M, Hovda DA, Shalmon E, Kelly DF, Vespa PM, Martin NA, Phelps ME, McArthur DL, Caron MJ, Kraus JF, Becker DP: Cerebral hyperglycolysis following severe traumatic brain injury in humans: a positron emission tomography study. J Neurosurg 1997, 86:241-251.

28. Vespa P, Bergsneider M, Hattori N, Wu HM, Huang SC, Martin NA, Glenn TC, McArthur DL, Hovda DA: Metabolic crisis without brain ischemia is common after traumatic brain injury: a combined microdialysis and positron emission tomography study. J Cereb Blood Flow Metab 2005, 25:763-774.

29. Glenn TC, Kelly DF, Boscardin WJ, McArthur DL, Vespa P, Oertel M, Hovda DA, Bergsneider M, Hillered L, Martin NA: Energy dysfunction as a predictor of outcome after moderate or severe head injury: indices of oxygen, glucose, and lactate metabolism. J Cereb Blood Flow Metab 2003, 23:1239-1250

30. Singh IN, Sullivan PG, Deng $Y$, Mbye LH, Hall ED: Time course of posttraumatic mitochondrial oxidative damage and dysfunction in a mouse model of focal traumatic brain injury: implications for neuroprotective therapy. J Cereb Blood Flow Metab 2006, 26:1407-1418

31. Clifton GL, Miller ER, Choi SC, Levin HS: Fluid thresholds and outcome from severe brain injury. Crit Care Med 2002, 30:739-745.

32. Juul N, Morris GF, Marshall SB, Marshall LF: Intracranial hypertension and cerebral perfusion pressure: influence on neurological deterioration and outcome in severe head injury. The Executive Committee of the International Selfotel Trial. J Neurosurg 2000, 92:1-6.

33. Robertson CS, Valadka AB, Hannay HJ, Contant CF, Gopinath SP, Cormio M Uzura M, Grossman RG: Prevention of secondary ischemic insults after severe head injury. Crit Care Med 1999, 27:2086-2095.

34. Brain Trauma F, American Association of Neurological S, Congress of Neurological S, Joint Section on N, Critical Care AC, Bratton SL, Chestnut RM, Ghajar J, McConnell Hammond FF, Harris OA, et al: Guidelines for the management of severe traumatic brain injury. IX. Cerebral perfusion thresholds. J Neurotrauma 2007, 24(Suppl 1):S59-S64.

35. Jaeger M, Schuhmann MU, Soehle M, Meixensberger J: Continuous assessment of cerebrovascular autoregulation after traumatic brain injury using brain tissue oxygen pressure reactivity. Crit Care Med 2006, 34:1783-1788.

36. Budohoski KP, Czosnyka M, de Riva N, Smielewski P, Pickard JD, Menon DK Kirkpatrick PJ, Lavinio A: The relationship between cerebral blood flow autoregulation and cerebrovascular pressure reactivity after traumatic brain injury. Neurosurgery 2012, 71:652-660. discussion 660-651.

37. Steiner LA, Czosnyka M, Piechnik SK, Smielewski P, Chatfield D, Menon DK, Pickard JD: Continuous monitoring of cerebrovascular pressure reactivity allows determination of optimal cerebral perfusion pressure in patients with traumatic brain injury. Crit Care Med 2002, 30:733-738. 
38. Scheufler KM, Rohrborn HJ, Zentner J: Does tissue oxygen-tension reliably reflect cerebral oxygen delivery and consumption? Anesth Analg 2002 95:1042-1048. table of contents.

39. Doppenberg EM, Zauner A, Bullock R, Ward JD, Fatouros PP, Young HF: Correlations between brain tissue oxygen tension, carbon dioxide tension, $\mathrm{pH}$, and cerebral blood flow-a better way of monitoring the severely injured brain? Surg Neurol 1998, 49:650-654.

40. Hemphill JC 3rd, Smith WS, Sonne DC, Morabito D, Manley GT: Relationship between brain tissue oxygen tension and $C T$ perfusion: feasibility and initial results. AJNR Am J Neuroradiol 2005, 26:1095-1100.

41. Rosenthal G, Hemphill JC 3rd, Sorani M, Martin C, Morabito D, Obrist WD Manley GT: Brain tissue oxygen tension is more indicative of oxygen diffusion than oxygen delivery and metabolism in patients with traumatic brain injury. Crit Care Med 2008, 36:1917-1924.

42. Nortje J, Coles JP, Timofeev I, Fryer TD, Aigbirhio FI, Smielewski P, Outtrim JG, Chatfield DA, Pickard JD, Hutchinson PJ, et al: Effect of hyperoxia on regional oxygenation and metabolism after severe traumatic brain injury: preliminary findings. Crit Care Med 2008, 36:273-281.

43. Oddo M, Nduom E, Frangos S, MacKenzie L, Chen I, Maloney-Wilensky E, Kofke WA, Levine JM, LeRoux PD: Acute lung injury is an independent risk factor for brain hypoxia after severe traumatic brain injury. Neurosurgery 2010, 67:338-344.

44. Oddo M, Levine JM, Kumar M, Iglesias K, Frangos S, Maloney-Wilensky E, Le Roux PD: Anemia and brain oxygen after severe traumatic brain injury. Intensive Care Med 2012, 38:1497-1504.

45. Soehle $M$, Jaeger $M$, Meixensberger J: Online assessment of brain tissue oxygen autoregulation in traumatic brain injury and subarachnoid hemorrhage. Neurol Res 2003, 25:411-417

46. Brain Trauma F, American Association of Neurological S, Congress of Neurological S, Joint Section on N, Critical Care AC, Bratton SL, Chestnut RM, Ghajar J, McConnell Hammond FF, Harris OA, et al: Guidelines for the management of severe traumatic brain injury. $X$. Brain oxygen monitoring and thresholds. J Neurotrauma 2007, 24(Suppl 1):S65-S70.

47. Ract C, Le Moigno S, Bruder N, Vigue B: Transcranial Doppler ultrasound goal-directed therapy for the early management of severe traumatic brain injury. Intensive Care Med 2007, 33:645-651.

48. Coles JP, Fryer TD, Coleman MR, Smielewski P, Gupta AK, Minhas PS, Aigbirhio F, Chatfield DA, Williams GB, Boniface $S$, et al: Hyperventilation following head injury: effect on ischemic burden and cerebral oxidative metabolism. Crit Care Med 2007, 35:568-578.

49. Coles JP, Minhas PS, Fryer TD, Smielewski P, Aigbirihio F, Donovan T, Downey SP, Williams G, Chatfield D, Matthews JC, et al: Effect of hyperventilation on cerebral blood flow in traumatic head injury: clinical relevance and monitoring correlates. Crit Care Med 2002, 30:1950-1959.

50. Rangel-Castilla L, Lara LR, Gopinath S, Swank PR, Valadka A, Robertson C Cerebral hemodynamic effects of acute hyperoxia and hyperventilation after severe traumatic brain injury. J Neurotrauma 2010, 27:1853-1863.

51. Czosnyka M, Smielewski P, Piechnik S, Steiner LA, Pickard JD: Cerebral autoregulation following head injury. J Neurosurg 2001, 95:756-763.

52. Beynon C, Kiening KL, Orakcioglu B, Unterberg AW, Sakowitz OW: Brain tissue oxygen monitoring and hyperoxic treatment in patients with traumatic brain injury. J Neurotrauma 2012, 29:2109-2123.

53. Velly L, Pellegrini L, Guillet B, Bruder N, Pisano P: Erythropoietin 2nd cerebral protection after acute injuries: a double-edged sword? Pharmacol Ther 2010, 128:445-459.

54. Bouzat P, Francony G, Thomas S, Valable S, Mauconduit F, Fevre MC, Barbier EL, Bernaudin M, Lahrech H, Payen JF: Reduced brain edema and functional deficits after treatment of diffuse traumatic brain injury by carbamylated erythropoietin derivative. Crit Care Med 2011, 39:2099-2105.

55. Bouzat P, Millet A, Boue Y, Pernet-Gallay K, Trouve-Buisson T, GaideChevronnay L, Barbier EL, Payen JF: Changes in brain tissue oxygenation after treatment of diffuse traumatic brain injury by erythropoietin. Crit Care Med 2013, 41:1316-1324

56. Hillered L, Vespa PM, Hovda DA: Translational neurochemical research in acute human brain injury: the current status and potential future for cerebral microdialysis. J Neurotrauma 2005, 22:3-41.

57. Timofeev I, Carpenter KL, Nortje J, Al-Rawi PG, O'Connell MT, Czosnyka M, Smielewski P, Pickard JD, Menon DK, Kirkpatrick PJ, et al: Cerebral extracellular chemistry and outcome following traumatic brain injury: a microdialysis study of 223 patients. Brain 2011, 134:484-494.
58. Sarrafzadeh AS, Sakowitz OW, Callsen TA, Lanksch WR, Unterberg AW: Bedside microdialysis for early detection of cerebral hypoxia in traumatic brain injury. Neurosurg Focus 2000, 9:e2

59. Oddo M, Villa F, Citerio G: Brain multimodality monitoring: an update. Curr Opin Crit Care 2012, 18:111-118.

60. Messerer M, Daniel RT, Oddo M: Neuromonitoring after major neurosurgical procedures. Minerva Anestesiol 2012, 78:810-822.

61. Oddo M, Levine JM, Frangos S, Maloney-Wilensky E, Carrera E, Daniel RT, Levivier M, Magistretti PJ, LeRoux PD: Brain lactate metabolism in humans with subarachnoid hemorrhage. Stroke 2012, 43:1418-1421.

62. Oddo M, Schmidt JM, Carrera E, Badjatia N, Connolly ES, Presciutti M, Ostapkovich ND, Levine JM, Le Roux P, Mayer SA: Impact of tight glycemic control on cerebral glucose metabolism after severe brain injury: a microdialysis study. Crit Care Med 2008, 36:3233-3238.

63. Vespa PM: The implications of cerebral ischemia and metabolic dysfunction for treatment strategies in neurointensive care. Curr Opin Crit Care 2006, 12:119-123.

64. Choi IY, Lee SP, Kim SG, Gruetter R: In vivo measurements of brain glucose transport using the reversible Michaelis-Menten model and simultaneous measurements of cerebral blood flow changes during hypoglycemia. J Cereb Blood Flow Metab 2001, 21:653-663.

65. Oddo M, Schmidt JM, Mayer SA, Chiolero RL: Glucose control after severe brain injury. Curr Opin Clin Nutr Metab Care 2008, 11:134-139.

66. Vespa P, McArthur DL, Stein N, Huang SC, Shao W, Filippou M, Etchepare M, Glenn T, Hovda DA: Tight glycemic control increases metabolic distress in traumatic brain injury: a randomized controlled within-subjects trial. Crit Care Med 2012, 40:1923-1929.

67. Magnoni S, Tedesco C, Carbonara M, Pluderi M, Colombo A, Stocchetti N: Relationship between systemic glucose and cerebral glucose is preserved in patients with severe traumatic brain injury, but glucose delivery to the brain may become limited when oxidative metabolism is impaired: implications for glycemic control. Crit Care Med 2012, 40:1785-1791.

68. Zafar SN, labal A, Farez MF, Kamatkar S, de Moya MA: Intensive insulin therapy in brain injury: a meta-analysis. J Neurotrauma 2011, 28:1307-1317.

69. Bouzier-Sore AK, Voisin P, Canioni P, Magistretti PJ, Pellerin L: Lactate is a preferential oxidative energy substrate over glucose for neurons in culture. J Cereb Blood Flow Metab 2003, 23:1298-1306.

70. Schurr A, Payne RS, Miller JJ, Rigor BM: Brain lactate, not glucose, fuels the recovery of synaptic function from hypoxia upon reoxygenation: an in vitro study. Brain Res 1997, 744:105-111.

71. Gallagher CN, Carpenter KL, Grice P, Howe DJ, Mason A, Timofeev I, Menon DK, Kirkpatrick PJ, Pickard JD, Sutherland GR, Hutchinson PJ: The human brain utilizes lactate via the tricarboxylic acid cycle: a 13C-labelled microdialysis and high-resolution nuclear magnetic resonance study. Brain 2009, 132:2839-2849.

72. van Hall G, Stromstad M, Rasmussen P, Jans O, Zaar M, Gam C, Quistorff B, Secher $\mathrm{NH}$, Nielsen HB: Blood lactate is an important energy source for the human brain. J Cereb Blood Flow Metab 2009, 29:1121-1129.

73. Maran A, Cranston I, Lomas J, Macdonald I, Amiel SA: Protection by lactate of cerebral function during hypoglycaemia. Lancet 1994, 343:16-20.

74. Smith D, Pernet A, Hallett WA, Bingham E, Marsden PK, Amiel SA: Lactate: a preferred fuel for human brain metabolism in vivo. $J$ Cereb Blood Flow Metab 2003, 23:658-664.

75. Ichai C, Armando G, Orban JC, Berthier F, Rami L, Samat-Long C, Grimaud D, Leverve $X$ : Sodium lactate versus mannitol in the treatment of intracranial hypertensive episodes in severe traumatic brain-injured patients. Intensive Care Med 2009, 35:471-479.

doi:10.1186/2110-5820-3-23

Cite this article as: Bouzat et al:: Beyond intracranial pressure: optimization of cerebral blood flow, oxygen, and substrate delivery after traumatic brain injury. Annals of Intensive Care 2013 3:23. 